CASES 1 and 2.-On April 27th I was called to see two children in Bouverie-road, Stoke Newington, the house being the last but one in the road, having the open country beyond. The younger of the two, aged eight years, had been ill for four days, and had slept with her sister, aged ten years. Both cases were mild. There was a good deal of false membrane on the tonsils, fauces, and velum palati in the younger child, and on two occasions traces of albumen in the urine. In both cases the temperature varied from $101^{\circ}$ to $103^{\circ}$, and the pulse from 120 to 130 . The pulse of the younger child was very feeble during the second week, and there was considerable glandular enlargement in the neck. The treatment used in these two cases was large doses of tincture of perchloride of iron and chlorate of potash internally, and glycerine of carbolic acid applied to the throat. Ice to suck, and plenty of port wine, beef-tea, and milk. In this house I found that previous to the attack the closet had been out of order for a week. There was no water, from something having gone wrong with the closet-wire.

CASE 3,-On the 8th of May I saw for the first time Mrs. W-, aged sixty-eight years. She was visiting at Albion-road, Dalston. She complained of slight sore-throat and cough; she was a little feverish. On examination the throat was a little inflamed; there were other symptoms of catarrh. Ordered a saline mixture. On the 9 th she felt much better, and the throat was comfortable. I did not therefore examine the throat. With the stethoscope I heard some coarse mucous râles. On the 10th there were more distinct bronchial symptoms, and no complaint was made about the throat. Ordered bark and ammonia. I saw her again on the evening of the 10th. She was then very restless and coughing; temperature $101.8^{\circ}$. On the morning of the 11th, at 11 A.M., I again saw her. She was much worse, and complained of her throat, and of great difficulty of swallowing. I found now that both the tonsils and the back of the fauces, as far down as $I$ could see, were covered with a thick diphtheritic exudation. The pulse was good and the temperature slightly subnormal. To take as much stimulants as possible. At 4 P.M. Dr. Wilson Fox saw the lady with me. She had grown worse rapidly since the morning; the disease had extended to the larynx, the face and left hand were getting livid, and very little air entered the left lung. ' The question of tracheotomy was discussed by Dr. Wilson Fox and myself, and decided against. The patient died during the evening.

CASE 4.-Miss W-_, daughter of the last patient, came to be with her mother on the 10th of May, and certainly kissed her mother on that day. I saw this lady on the evening of May 13th, exactly three days from the time she came to attend her mother, and she had undoubted diphtheria. There were distinct patches of false membrane on the throat. Temperature $103^{\circ}$. She was removed the same evening into a private ward in a hospital, and recovered.

CASES 5, 6, and 7.-These occurred at the same house in Mountford-road, Hackney. Mrs. B-, who had been confined on the 6th of May, complained of sore-throat on May 15th, so also, on the same day, did her eldest son, aged eight years. Both cases were slight, and there was not much exudation on the throat. On May 19th, four days after the mother was taken ill, the nurse called my attention to the infant's navel. The funis had separated, and round the navel was a red circle as large as the top of a tumbler, and this was covered with a shreddy diphtheritic exudation perfectly characteristic. It was not easy to examine the throat, but, as far as I could see, there was membrane there also. The infant died on the fourth day. The mother and son recovered. The treatment was the same as in cases 1 and 2 . CASES $8,9,10$. - I was called on the 14th of May to see Mrs. G-, living in a large roomy house, having the open country behind it, in Lordship-park, South Hornsey. found her suffering from a severe attack of diphtheria.

was very ill, temperature $103 \cdot 2^{\circ}$, with a good deal of exuda. tion on the throat. The glands of the neck were intensely painful and much swollen. She recovered very slowly, and is much shattered in health by the attack. No albumen and no paralysis. She was of course isolated, but on the 22nd her second daughter, aged thirteen years, was attacked very seriously. The entire throat was covered with false membrane, which extended over the roof of the mouth. Temperature $102 \cdot 2^{\circ}$; pulse 112 ; the latter became so feeble after a few days that it could scarcely be felt. Urine feebly albuminous twice. Could only swallow with the greatest difficulty. Glands painful, and considerable aphonia. The treatment was, as in the other cases, plenty of wine, steel and chlorate of potash, ice, beef-tea, milk, and glycerine of carbolic acid applied to the throat; she also had the throat frequently sprayed with warm Condy's fluid and water. She is recovering slowly, the pulse being still almost imperceptible. On May 28th, her sister, aged fourteen years, had several characteristic patches on the throat, but was not at all ill. Temperature $99^{\circ}$; pulse 80 . The state of the throat continued for several days, and then cleared off, the patient all the time feeling fairly well.

CASES 11 and 12.-Agnes B-_ aged eight years, was attacked with a sickness and sore-throat on the 25th of May. She had had scarlet fever two years back, but her mother thought she must be getting it again. Her temperature was $103^{\circ}$; pulse 120 . There were several large diphtheritic patches on the throat, the tongue was swollen, and she conld scarcely swallow. The urine was highly albuminous. The treatment was the same as in the other cases. On the fourth day her nose bled profusely. She said she felt much better. The throat cleared ; the temperature was $98^{\circ}$; pulse 76. The albumen disappeared from the nrine, and, beyond weakness, the patient was well on May 31st. Her sister Lilly sickened two days later, and made a speedy recovery.

CASES 13, 14, and 15.-These were all mild, requiring no particular remarks. One was in Albert-road, Dalston, and the house was nearly opposite to that in which cases 11 and 12 were. The other two cases were in Stoke Newington.

It will be seen by the above necessarily brief notes (for I have omitted all details) that in less than a month fifteen cases of diphtheria occurred in my practice, two proving fatal. In all the cases isolation was insisted on, and disinfection with carbolic acid carried out fully. I also advised the various members of each household to gargle their throats very frequently with Condy's fluid and water, and to these precautions I attribute the escape of the other members of the different households. In the houses in Albertroad, there were eleven persons living in one house, and only one had the disease, and in the other house eight persons lived, and but two had diphtheria. None of the patients have as yet developed diphtheritic paralysis. Queen's-road, Dalston.

\section{TARSAL TUMOURS TREATED BY ELECTROLYSIS.}

Bx JULIUS ALTHAUS, M.D.

ON February 6th, 1880, Mr. White Cooper sent a lady, aged thirty, to me, who suffered from tarsal tumours occupying nearly the whole of both upper eyelids, and which had become gradually developed during the last six months. They looked inflamed, were very disfiguring, and caused considerable annoyance by interfering with the proper action of the eyelids, which felt very heavy. Under these circumstances $\mathrm{Mr}$. White Cooper recommended the removal of the growths by electrolysis. As the conjunctiva was involved by the tumour and was excessively sensitive, reflex action in the lid being very much increased, I thought it best to perform the operation under anæsthesia, and therefore procured the assistance of Mr. Clover, who put the lady very quickly under the influence of his anæsthetic mixture. I then applied both poles of the voltaic battery by means of my four-pointed electrolytic needle-conductors alternately to both tumours, so that each of them received the influence of the cathode and anode successively. Twenty cells of Becker-Muirhead's battery were used for ten minutes, after which the whole of the tumours, both inside and outside, appeared completely shrivelled up.

Not a drop of blood was lost at any stage of the operation, which was particularly remarkable when the subconjunctival portion of the tumour was acted upon, as this was highly vascular. The surface of the lids was covered by goldbeater's skin and flexile collodion. The patient recovered quickly from the influence of the anæsthetic, and went the same afternoon to her home in the country. She called upon me again on March 4th, about a month after the operation, when I was gratified to find that the success had been complete. The tumours had entirely vanished; no scar was visible anywhere, and no eversion of the lids had occurred. Both eyelids had, indeed, a perfectly normal appearance.

Tarsal tumour is a troublesome affection and does not yield to external applications, such as the red precipitate or iodide 
of potassium ointment; so that, if removal becomes necessary, free incisions have to be made which are generally acconpanied by considerable bleeding. The adhesive inflammation which supervenes upon the operation has sometimes to be increased by touching the interior of the cysts with nitrate of silver; and if the tumour be situated near the margin of the eyelid and the punctum, there may be cicatricial shrinking after the operation, and eversion of the edgc of the lid, with displacement of the punctum. All this makes the ordinary operation for tarsal tumour a somewhat formidable one; and electrolysis would therefore appear far preferable. The complete absence of bleeding in the latter procedure is a great advantage, as the operator sees much better what he is doing, and can regulate the action of the galvanic force with the greatest nicety. A single application appears to be sufficient for a cure, and there is no danger of cicatricial shrinking afterwards, provided the operation be properly performed. In a case where only the skin of the eyelid would be affected, I should not resort to anæsthesia, as then the pain would not be severe; but the great sensitiveness of the mucous membrane in the above case rendered anæesthesia desirable.

Bryanston-street, Marble Arch, W.

\section{A}

\section{HOSPITAL PRACTICE, BRITISH AND FOREIGN.}

Nulla autem est alia pro certo noscendi via, nisi quamplurimas et morbornm et dissectionum historias, tum aliorum tum proprias collectas habere, et inter se comparare.-Mongagri De Sed. et Caus. Morb., lib.iv. Proomium.

\section{ST. GEORGE'S HOSPITAL.}

THE following are among some of the cases, under the care of Mr. CARTER, in the Ophthalmic Wards.

SOFT CATARACT IN ONE EYE, AND A HIGH DEGREE OF MYOPIA IN THE OTHER, BOTH RECENT.

The patient, a man aged twenty-four, eighteen months ago was tested for the army, and the sight of each eye was found to be perfect. Five months ago he noticed that the sight of the left eye was failing, and a month later that he had a difficulty in making out distant objects with the right. When admitted, the right eye was much larger than the left, especially in the antero-posterior diameter. Myopia $=16 \mathrm{D}$, and there was a large posterior staphyloma. The left eye resembled a hypermetropic eye in size and shape. The lens was universally opaque. The latter was removed by suction.

DISLOCATION OF THE LENS INTO THE VITREOUS.

The patient, a man aged sixty-four, received a blow on the eye. Vision was immediately reduced to perception of light. When admitted, there was conjunctival injection, a tremulous and inactive iris, and the fundus oculi could not be illuminated. Four days later, no details of fundus were visible, and there were floating filaments in the vitreous. The lens was not visible. Vision : counts fingers at three feet.

\section{VICTORIA DOCK DISTRICT DISPENSARY.}

\section{CASE OF MALFORMATION OF HEART AND ABSCESS OF} BRAIN; UNUSUAL CONTENTS.

(Under the care of Mr. JULIUS CAESAR.)

E. $\mathbf{M}-$, aged nine, first came under observation in December, 1879, with the following history :- $\mathrm{He}$ was a full time and healthy child when born. At three months old his mother noticed that his cheeks, a circle round lips, the tips of fingers and nails, were very blue, and that the colour increased if he were excited or cried. At the same time the ends of the fingers and the toes began to enlarge.

These symptoms increased, but otherwise he appeared to enjoy good health up to about twelve months old, when a discharge, not offensive, from the left ear took place. At this time, also, he used to clutch his head as if it were the seat of great pain, and when old enough to make himself understood used to complain of great pain there. When eighteen months old he had measles, bronchitis, and pneumonia, but appeared to recover from them fairly well. When three years old he had completed dentition. The discharge from the ear now ceased, and he began to walk ; he was not at any period able to walk more than half a mile without fatigue and difficulty in breathing. Between five and six years his mother noticed, for the first time, that he dragged his right leg as if he had not power at the hip to lift it Shortly after this his right wrist began to fail, then his forearm, and, finally, his entire arm. Then the leg became affected, the paralysis appearing to begin in the hip, and gradually extending to the foot, till at seven years and a half he had lost all power over these extremities, which about this time got acutely sensitive, so much so that the least movement of them caused him to cry, even touching them appeared to give him great pain. He had never talked plainly, but about seven years his articulation got very diff. cult and hesitating, till at last he could utter only balf words. As for "mother" he used to say " mur," and for "father" "f-a-a." At all seasons of the year he felt cold to the touch, and used to complain of feeling cold, though clothed in flannel.

On August 18th last he had a convulsive fit during the night. When seen in the morning he was in bed comatose, and quite unconscious, the pupils were widely dilated, and his forehead suffused with a very deep blush. The pulse was rapid, full, and strong. He was unable to swallow even liquids. All his evacuations were passed involuntarily. He remained in this state for five days, and then appeared to get a little better, took some milk and egg, and seemed to recognise those about him. This continued for three days, when he relapsed into his former state of unconsciousness, which lasted till he died on August 31st.

At the necropsy thirty hours after death the pulmonary artery was found to communicate with the aorta a little way above the attachment of the two most left semilunar valves by an opening about the size of a sixpenny piece. These valves were perforated in several places. The ascending part of the aorta was as big as that of an adult. No murmurs were heard during life. The right lung was adherent to the thoracic wall and diaphragm, and both were the seat of tubercle. In removing the brain great difficulty was ex. perienced in detaching the calvaria, so adherent was the dura mater to it. On examining the brain tubercles were seen scattered all over the base, and in the ventricles and fissures of Sylvius. The right hemisphere of the cerebrum was quite pulpy, the anterior part of the left hemisphere was in a like condition, but the middle and posterior lobes were quite hard except at one"spot in the latter lobe, which was quite soft and fluctuated on pressure. On cutting into this spot it proved to be a large abscess extending from the middle cornu to the posterior cornu of the lateral ventricle, but not entering it. On examining the abscess it was found to contain a dense calcareous mass weighing 120 grains. The walls of the abscess were impregnated with a like material, and grated on the knife when cut. The remainder of the brain presented no pathological changes of importance.

Remarks. - The principal points of interest in this case were (1) the unusual form of heart malformation ; (2) the existence of large perforations in the semilunar valves, unaccompanied by murmur; (3) the existence of so much brain mischief with comparatively so few symptoms.

\section{QUEEN'S HOSPITAL, BIRMINGHAM.}

COMPOUND COMMINUTED FRACTURE OF THE HUMEROS; LISTERISM ; RECOVERY.

(Under the care of Mr. JAMES F. WEST.)

THE following cases, of which the notes are abridged from those taken by Mr. J. W. Moore, house-surgeon, serve to illustrate the advantage of the antiseptic treaiment in severe compound and comminuted fractures.

Charles F-_-, aged thirty-five, a saddler, was admitted on July 10th, 1880. He had been thrown off the top of an omnibus, and had fallen with his left arm doubled under him. The humerus was fractured just above the insertion of the deltoid, and again about three inches lower down. There were two small wounds on the inner side of the arm at the upper third, a little towards the back. He had lost about a pint of blood, and there was considerable shock. A piece of bone, about two inches in length and one-third of the circumference of the shaft of the humerus, protruded 